\title{
EL REFERENTE HOMÉRICO EN LAS EPIFANÍAS VIRGILIANAS
}

\author{
María Ángeles Fernández Contreras
}

\begin{abstract}
The authoress reviews all the epiphanies displayed by Virgilian gods in the Aeneid. Through a systematic study of their patterns, typical features and narrative contexts, she tries to discem how much they are based on Homeric epiphany-scenes.
\end{abstract}

En la Eneida de Virgilio, como en la Ilíada y la Odisea, sucede ocasionalmente que un dios considera oportuno descender a la esfera humana y hacerse presente a algún héroe para influir en su ánimo y sugerirle planes de actuación concretos. En la épica virgiliana, al igual que en la homérica, la epifanía está entre los resortes que el dios tiene a su alcance para orientar e inclinar en un cierto sentido la marcha de los acontecimientos. Realizada ya para resolver, ya para perturbar un estado de cosas, la intromisión de los dioses en el escenario y la peripecia humanos evidencia ante todo que en la esfera divina existe un alto grado de atención y de preocupación por cuanto acontece en el ámbito de los hombres. Asimismo se pone de manifiesto el alto nivel de comunicación y accesibilidad que se establece entre los dos mundos: "no existe una frontera infranqueable, sino, al menos en la dirección de los dioses hacia los hombres, extremadamente permeable"1. Gracias a la eventual injerencia divina, el poeta épico consigue además que la acción adquiera una trascendencia y un tono especiales: el suceso extraordinario e inesperado que la epifanía representa, concede al instante narrativo el halo de grandeza, solemnidad y privilegio que mejor se adecua a la peripecia heroica y que más conviene a la talla y entidad de los personajes ${ }^{2}$.

Llegado el instante de narrar la aparición de la deidad, Virgilio trata la realidad física de ésta con una reticencia que podemos considerar de cuño homérico ${ }^{3}$. Por lo común, ni Homero ni Virgilio permiten que la figura divina quede representada o trazada de modo nítido. Aun allí donde se intuye que el personaje puede estar beneficiándose de la contemplación plena de la deidad, se suele optar por escatimar al lector gran parte de los detalles descriptivos que mejor podrían ayudarle a discernir qué es exactamente lo que está viendo el mortal. Hay que admitir que Virgilio suele ser, en cualquier caso, algo más generoso que Homero a la hora de aludir a elementos corporales precisos. En la Ilíada la presencia de Atena ante Aquiles (1.200), en la que constituye una de las epifanías más

\footnotetext{
1 M. Brioso Sánchez, "El concepto de divinidad en las Argonáuticas de Apolonio de Rodas" (en prensa, en un volumen colectivo editado por J. A. López Férez).

${ }^{2}$ Cf. P. Pucci, "Strategia epifanica e intertestualità nel secondo libro dell’Iliade", SIFC 81 (1988), p. 5.

${ }^{3}$ Cf. P. Pucci, "Epifanie testuali nell'Iliade", SIFC 78 (1985), pp. 176 ss.
} 
explícitas de todo el poema, es planteada a través de la mención únicamente de los extraordinarios ojos de la diosa. En la aparición de Afrodita ante Hélena (3.395 ss.) se alude a los ojos, el busto y el cuello sobrehumanos. En uno y otro caso asistimos al uso de un tipo de sinécdoque que Homero no vuelve a utilizar en ningún otro momento de su obra y que realmente trasciende y supera la austeridad y parquedad de datos imperantes en todas las demás apariciones. Tal procedimiento un tanto excepcional es el que Virgilio, por su parte, ha tomado como punto de referencia o partida a la hora de elaborar las escenas de teofanía de la Eneida. No por desear apartarse de la sobriedad que es típica en Homero, deja, pues, Virgilio de utilizar a éste como referencia. La aparición del dios se suele concretar en el poema virgiliano a través de la mención de un elenco más o menos breve de elementos pertenecientes al físico genuino del dios: las alas, los ojos y la boca rosada de Iris (5.647 ss., 9.5); los pies, la voz, los cabellos rubios, el color corporal y los miembros de Mercurio (4.259, 556 ss.); en el tratamiento dado a una de las epifanías de Venus (1.402 ss.) hay incluso una aproximación a la largueza de detalles que podemos encontrar en los himnos homéricos (h. Cer. 275 ss., Ven. 170 ss.). Virgilio dispensa también, por otra parte, una gran atención a la reacción y al estado anímico del mortal visitado. De los efectos psicológicos provocados por la aparición se preocupa Homero sólo muy raramente. Los esporádicos casos en que esto sucede son asimismo, como se verá, los que a Virgilio, deseoso de dar relevancia a la manera en que el mortal puede vivir o sufrir la epifanía, le han servido como punto de referencia.

No faltan en el poema épico virgiliano epifanías desarrolladas únicamente a través de la voz. Considérese la escena protagonizada por Cibeles en 9.110 ss., donde, en cualquier caso, precede un aviso o señal visual que, por sorprendente, compensa con creces la invisibilidad de la diosa: un resplandor deslumbrante cruza el cielo por la parte oriental ("noua lux oculis offulsit et ingens / uisus ab Aurora caelum transcurrere nimbus", $110 \mathrm{~s}$.). Cuando la diosa frigia se hace oír ("tum uox horrenda per auras / excidit", 112 s.), su voz inunda la armada y todo el escenario. Sigue el prodigio operado por la deidad: la metamorfosis de las naves en Ninfas (116 ss.). A la vista de éstas (una segunda epifanía), los rútulos quedan estupefactos (123), Mesapo se aterra (123 s.) y el Tíber detiene y hace retroceder el curso de sus aguas (125). En 3.93 ss. Apolo deja oír su voz desde el adyton de su templo ${ }^{4}$. También en este caso preceden señales portentosas: el temblor del monte y de los umbrales y el laurel del dios (90 ss.). En ambos episodios está mucho más claro que en los casos homéricos comparables ${ }^{5}$ que la única manifestación de la deidad es propiamente la de la voz.

Por lo demás, la presencia del dios es visualizada en un total de catorce escenas. Seis de tales intervenciones son realizadas o iniciadas con la utilización de un disfraz (regularmente, y exceptuando sólo un caso, de un personaje que al mortal visitado le es familiar). Alecto y Somnus son las criaturas que usan el elemento de la máscara con fines

\footnotetext{
${ }^{4}$ Cf. R. Heinze, Virgil's epische Technik (Stuttgart 1965), p. 311, n. 1.

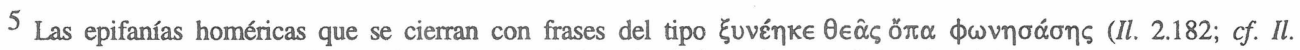
$10.512,20.380, O d .24 .535$ ) y en las que no se habla de disfraz ni se explicita si el héroe realmente ve algo. La epifanía a través exclusivamente de la voz no es cosa normal en la Odisea; en la Ilíada, en cambio, es bastante frecuente.
} 
más crueles. Iris transfigurada en Béroe, y Venus con aspecto de cazadora, juegan ligeramente a confundir a los mortales. Los disfraces de Apolo y de la ninfa Iuturna secundan intervenciones innocuas y hasta un tanto benévolas. Únicamente Iuturna tiene la ocurrencia de travestirse de personaje del sexo contrario, algo que la aproxima a la Atena homérica ${ }^{6}$. Somnus es el único que mantiene hasta el final de su visita la ilusión creada por la máscara. Alecto-Cálibe, Iris-Béroe, Venus-cazadora, Iuturna-Metisco y Apolo-Butes terminan su intervención deshaciéndose del disfraz y consintiendo que el mortal finalmente perciba la verdad. Del disfraz prescinden por completo tres dioses olímpicos (Mercurio, Iris, Venus) y una serie de deidades menores (Penates, Tiberino, Ninfas). Asistimos, por otra parte, a la llamativa circunstancia de que seis apariciones quedan insertadas en el contexto del reposo nocturno, lo cual, como en su momento se verá, no carece de antecedentes homéricos ${ }^{7}$.

La primera escena que vamos a revisar, 4.222 ss., muestra que Virgilio ha sido sensible a la concatenación de instantes que en Homero configura la escena típica de embajada o recado $^{8}$ con mensajero divino, tipo complejo de escena en el que se engarzan y suceden la encomienda de portar un mensaje, una escena de desplazamiento y llegada ${ }^{9}$, y la epifanía propiamente dicha. Júpiter presta oído a las preces que acaba de hacerle Iarbas ("audiit Omnipotens", 220) y se vuelve a Mercurio para encomendarle la transmisión a Eneas de un mensaje ("tum sic Mercurium adloquitur ac talia mandat", 222)10. Al discurso de Júpiter (223-237) sigue una frase de inspiración netamente homérica: la que da cuenta de la disposición de Mercurio a obedecer ("ille patris magni parere parabat / imperio", 238 s.), recuerdo y desarrollo de la fórmula que cierra en Homero el momento del encargo de la

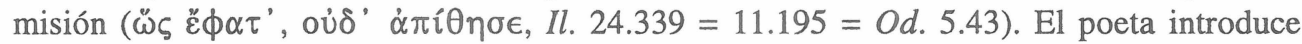
entonces una escena de pertrechamiento que recuerda las protagonizadas por Hermes en $I l$. 24.340 ss. y $O d .5 .44$ ss. Mercurio se prepara para partir calzándose los talares ("primum pedibus talaria nectit / aurea, quae sublimem alis siue aequora supra / seu terram rapido pariter cum flamine portant", 239 ss.) $)^{11}$ y empuñando el caduceo ("tum uirgam capit",

6 Atena, cuya afición en este sentido sólo es compartida por Hera (únicamente en $I l .5 .785$ ss.), llega a adoptar la imagen de heraldo (Il. 2.280 ss.), Laódoco (3.86 ss.), Fénix (17.555 ss.), Deífobo (22.226 ss.), Méntor (Od. 3.371 ss.), pastor (13.221 ss.).

${ }^{7}$ El número de casos hace pensar en una auténtica afición por parte de Virgilio a dar un escenario nocturno a la aparición divina. Con ello retoma lugares homéricos y además contesta al gusto helenístico por las epifanías del daemon meridianus (cf. T. D. Papanghelis, "About the hour of noon: Ovid, Amores 1.5", Mnemosyne 42 [1989], pp. 54 ss.).

${ }^{8}$ Cf. "Botenszene" en W. Arend, Die typischen Szenen bei Homer (Berlin 1933, reimpr. 1975), p. 54.

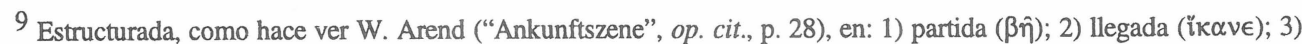
encuentro $(\epsilon \cup ๋ \rho \in v)$ del mortal buscado, cuya situación o actividad es descrita ("Situationschilderung"); 4) aproximación e inicio del discurso. Esporádicamente, el personaje se viste o pertrecha ("Rüstungsszene") antes de partir. Que el dios entre en contacto con el mortal tras moverse hacia él según los momentos de la escena convencional de llegada, hace que su aparecerse, al menos para el lector, no resulte instantáneo ni fortuito.

10 En Il. 24.333 ss. preceden a la embajada de Hermes: la plegaria de Príamo (306 ss.), la aceptación por parte de

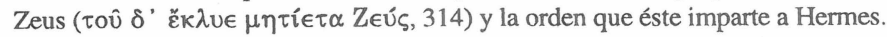

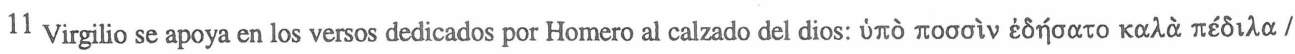


$242)^{12}$. El desplazamiento del dios cuenta con elementos de gusto homérico. La descripción de la ruta corresponde a la "Wegschilderung" que es típica en los movimientos realizados por deidades"13. En su vuelo, Mercurio divisa los costados de Atlante ("uolans apicem et latera ardua cernit", 246); sobre él se detiene ("hic primum paribus nitens Cyllenius alis / constitit", $252 \mathrm{~s}$.) para saltar hacia las aguas ("hinc toto praeceps se corpore ad undas / misit aui similis, quae circum litora, circum / piscosos scopulos humilis uolat aequora iuxta", 253 ss. $)^{14}$. En Od. 5.50 s. Hermes llega desde el Olimpo a Pieria y desde tal punto salta al mar

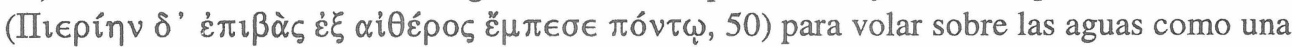
gaviota con dirección a la costa de Calipso. En tanto que el ave de Virgilio vuela muy bajo rasando el agua por los escollos en donde abundan los peces, la gaviota del símil homérico aparece ya en acción y va humedeciéndose las alas mientras pesca entre las olas: $\kappa \alpha \tau \grave{\alpha}$

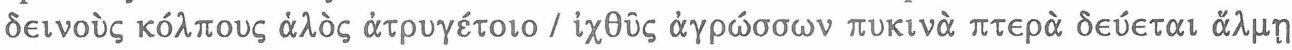
$(52 \mathrm{ss} .)^{15}$. Virgilio, a continuación, se atiene a la concatenación de momentos que es típica en la escena homérica de llegada. Detalla el arribo de Mercurio y el encuentro del personaje buscado, del que nos indica además la actividad en la que momentáneamente está ocupado: "ut primum alatis tetigit magalia plantis, / Aenean fundantem arces ac tecta nouantem / conspicit" (259 ss.). Cuando se trata de dioses que descienden, es típico en los épicos posteriores a Homero expresar la llegada con la indicación de que los pies tocan o se posan sobre el punto de destino ( $c f$. A. R. 2.548, Q. S. 7.561, 9.297 s.). La situación que la Odisea asigna con más frecuencia al personaje visitado es la celebración de un banquete ${ }^{16}$. Virgilio prefiere el asentamiento de ciudades y la asignación de leyes. "In den Situationsschilderungen offenbart sich der römische Gehalt der Aeneis" (W. Arend, op. cit., 143). Mercurio aborda a Eneas ("continuo inuadit", 265) y le transmite el mensaje que trae. Cumplida la misión, efectúa una escapada poco homérica: "tali Cyllenius ore locutus / mortalis uisus medio sermone reliquit / et procul in tenuem ex oculis euanuit auram" (276 ss.). El sobrenatural esfumarse, el deshacerse y desvanecerse ante los ojos de Eneas, contrasta con el carácter relativamente realista conferido a la aparición por el preámbulo del largo y detallado viaje de llegada. Frente a la aparición, que al menos para el lector no ha sido fortuita ni repentina, la marcha tiene un fuerte aspecto mágico e irreal. Téngase en cuenta que el desvanecerse en el aire es relegado por Homero a la retirada del $\epsilon i \tilde{\delta} \omega \lambda$ ov

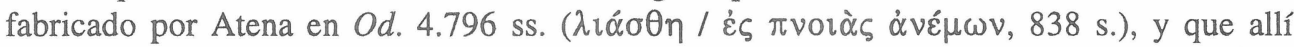

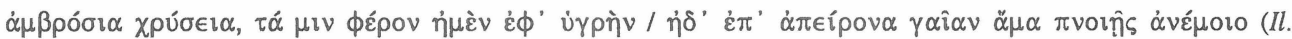
24.340 ss.). El autor latino emplea sólo un epíteto, frente a los tres homéricos, y una oración de relativo que contiene la misma idea básica expresada por la homérica.

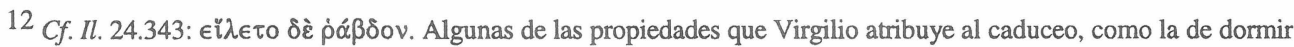
y la de despertar a los mortales (244), son también mencionadas en el texto homérico (Il. $24.343 \mathrm{~s}$.).

13 Cf. W. Arend, op. cit., p. 28, n. 2.

$14 C f$. el elenco de los lugares que va tocando Hera en $I l .14 .225$ ss.; $c f$. también 281 ss.

15 Sobre la convención homérica de ilustrar los desplazamientos divinos mediante símiles, véanse interesantes observaciones en T. Krischer, Formale Konventionen der homerischen Epik, Zetemata 56 (München 1971), pp. 19-23.

16 Véase al respecto C. Shelmerdine, "The Pattern of Guest Welcome in the Odyssey", CJ 65 (1969), pp. 124 s. Hay otras situaciones típicas: los personajes femeninos suelen ser encontrados ocupados en el telar (así sorprende IrisLaódice a Hélena en Il. 3.125 ss., Hermes a Calipso en Od. 5.61 s.). 
donde la marcha del dios es especificada, ésta regularmente adquiere la forma de un viaje hacia algún sitio muy preciso (el Olimpo en Od. 6.41 ss.; Atenas y la morada de Erecteo en 7.79 s.). Virgilio puede muy bien estar recordando lugares apolonianos: las Ninfas de Libia se eclipsan y disipan delante de Jasón (A. R. 4.1330 s.). En 4.1590 s. la imagen de Tritón se esfuma repentinamente en el aire.

La reacción de Eneas es bien singular. La visión lo ha dejado mudo y consternado ("aspectu obmutuit amens", 279), con síntomas inconfundibles de miedo ("arrectaeque horrore comae et uox faucibus haesit", 280) ${ }^{17}$. Como es sabido, que el miedo se apodere del mortal visitado es en Homero cosa muy excepcional: aunque a Príamo se le eriza el pelo en los miembros al ver a Hermes transfigurado en joven mirmidón (Il. 24.359), y lo asalta un temblor al ver y oír a Iris (170), lo más generalizado es que el héroe arcaico afronte la injerencia y la proximidad de la deidad con gran entereza (Il. 1.194 ss., 2.787 ss., 17.323 ss.). Al Eneas virgiliano por su parte, la circunstancia de ser hijo de diosa no le proporciona la seguridad con que Aquiles o Diomedes en la Ilíada son capaces de encarar cualquier aparición divina. En el troyano aflora más bien el sentimiento de la propia vulnerabilidad ante lo que resulta extraordinario y poco conocido, así como el respeto temeroso frente a la voluntad y los manejos divinos. La pérdida de la voz, de otra parte, está entre los efectos sufridos por Metanira ante la asombrosa epifanía de Deméter en el himno homérico

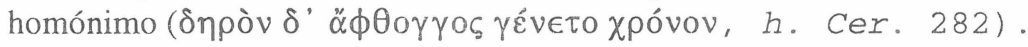

Eneas ha oído la voz y también ha visto con nitidez al dios. Así lo cuenta luego a Dido: "ipse deum manifesto in lumine uidi / intrantem muros uocemque his auribus hausi" (358 s.). Observación semejante hace Príamo al referir a su familia la aparición de Iris: ađv่ ò

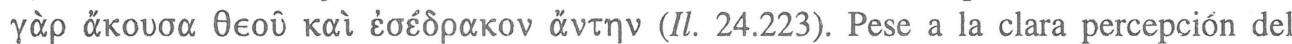
héroe, Virgilio, siguiendo la pauta homérica, no nos da datos que nos permitan reconstruir la imagen realmente contemplada. A nivel narrativo, la visita divina resulta muy efectiva: el héroe, sin aguardar ni un instante, urge a su gente a preparar la partida (281 ss.).

En el canto siguiente Juno ordena a Iris que vaya a presentarse en la escuadra troyana. No asistimos al discurso con el que la diosa da a la mensajera las posibles instrucciones. Tan sólo se nos dice que es Hera quien la ha puesto en movimiento: "Irim de caelo misit Saturnia Iuno / Iliacam ad classem uentosque aspirat eunti” $(5.606 \mathrm{~s} \text {. })^{18}$. La emisaria se deja caer veloz ("uiam celerans per mille coloribus arcum / nulli uisa cito decurrit tramite uirgo", 609 s.). Aprovecha el singular fenómeno atmosférico ${ }^{19}$ y desciende sin ser vista ("nulli uisa") 20 . Encuentra a los hombres ocupados en los juegos fúnebres ${ }^{21}$ ("conspicit

17 Se trata exactamente de los mismos síntomas que le provoca la aparición del espectro de Creúsa ("steteruntque comae et uox faucibus haesit", 2.774).

18 Recuérdense los casos homéricos en los que la "Auftragserteilung", en lugar de como un discurso, figura bajo la

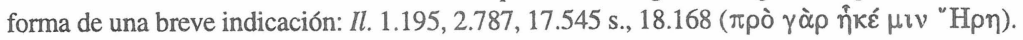

19 Recuerdo de $I l$. 17.547, donde Atena, que desciende a la llanura a instancias de Zeus, es comparada con el arco iris.

20 Atena, antes de asumir el aspecto de Laódoco, desciende desde el Olimpo como un meteoro (Il. 4.75 ss.). La visión de éste asombra a todos (79) e incluso provoca comentarios (81 ss.). La Iris virgiliana, como en general todos los dioses en Homero, puede decidir en qué momento preciso va a comenzar a ser visible. 
ingentem concursum et litora lustrat / desertosque uidet portus", $611 \mathrm{~s}$.) y a las mujeres apartadas en la playa llorando a Anquises: "at procul in sola secretae Troades acta / amissum Anchisen flebant, cunctaeque profundum / pontum aspectabant flentes" (613 ss.). Aparece ya en Homero, allí donde la visita es recibida por más de un personaje, esta suerte de división o desdoblamiento de la "Situationsschilderung". Al llegar a Ogygia, Hermes encuentra que, en tanto que Calipso teje en el interior de la morada (Od. $5.61 \mathrm{~s}$ ), Odiseo llora a solas en la playa ( $\dot{\varepsilon} \pi$ ' $\dot{\alpha} \kappa \tau \hat{\eta} \varsigma \kappa \lambda \alpha \hat{\imath} \epsilon \kappa \theta \hat{\eta} \mu \epsilon \nu \circ \varsigma, 5.81)$ y dirige los ojos hacia el mar

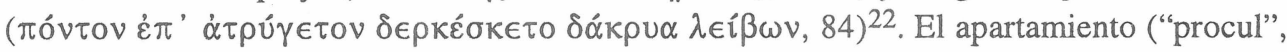
"in sola", "secretae") y la aflicción ("flebant", "flentes"), así como el escenario de la costa, son ingredientes que ya en Homero pueden propiciar una aparición: en Od. 13.219 ss. Odiseo llora y se arrastra sobre la orilla del mar antes de ver a Atena-pastor. A Telémaco se le aparece Atena-Méntor en la playa de Itaca (2.260 ss.), a donde se ha retirado a solas y contristado tras la asamblea. Sobre la playa de Faro, Idotea interpela a Menelao aprovechando el momento en que éste ha quedado apartado de los compañeros (4.367). Cf. también $I l .1 .349$ ss. Iris muta su propio aspecto antes de introducirse entre las mujeres; abandona su fisonomía y su vestidura de diosa y adopta la figura de una troyana: "inter medias sese haud ignara nocendi / conicit et faciemque deae uestemque reponit; / fit Beroe" (618 ss.). Como es típico en los disfraces homéricos de gente conocida, también Virgilio da datos biográficos: menciona al esposo y habla de la brillantez del linaje de Béroe (620 s.). La aparición es experimentada por todas las mujeres allí presentes ("Dardanidum mediam se matribus infert", 622), circunstancia que cuenta con antecedentes en Homero: Atenaheraldo en la asamblea (Il. 2.280 ss.); Ares-Acamante (5.461 ss.) y Hera-Esténtor (780 ss.) enardeciendo a los guerreros ${ }^{23}$. Una vez que Iris-Béroe ha pronunciado su doloso discurso y ha lanzado sobre las naves la antorcha encendida (641 ss.), Pirgo advierte a todas las otras que quien se les ha presentado no es realmente Béroe: "diuini signa decoris / ardentisque notate oculos, qui spiritus illi, / qui uultus uocisque sonus uel gressus eunti” (647 ss.). Las matronas asisten atónitas a la osada actuación de Iris-Béroe sin decidirse todavía a tomar parte. La vacilación les dura hasta el instante en que la diosa emprende su retirada: "cum dea se paribus per caelum sustulit alis / ingentemque fuga secuit sub nubibus arcum" (657 s.). La espectacularidad (la mención de las alas induce a pensar que el cuerpo de la diosa es realmente visible) y lo inesperado de esta partida hacen que las troyanas, estupefactas ("attonitae monstris actaeque furore", 659), se lancen sin escrúpulo contra las naves y las incendien con el fuego arrancado de los altares.

En este caso el autodesenmascaramiento funciona como acicate, es el resorte persuasivo, el estímulo que empuja a las mujeres a actuar como la diosa ha sugerido. Apréciese que el reconocimiento se ha efectuado realmente a partir de elementos diversos: a) señales externas cuales los ojos brillantes, el sonido de la voz o el paso (elementos que

\footnotetext{
21 Cf. A. R. 4.851 s. (en el contexto de la aparición de Tetis a Peleo).

22 Para explicar la segregación de las troyanas Williams (Aeneidos V. Commentary, p. 160) toma como referencia las circunstancias históricas: "they did not attend at ludi funebres in Rome, and Suetonius (Aug. 44) relates that Augustus excluded women from watching athletic competitions".
}

23 En A. R. la mayor parte de las epifanías, protagonizadas casi siempre por divinidades menores, son vividas por todo el grupo. Tan sólo Tetis es vista y oída únicamente por Peleo (4.854 s.). 
están ya presentes en los reconocimientos homéricos ${ }^{24}$, y que evidencian la complacencia del dios en consentir que rasgos y características extraordinarios hagan al mortal intuir la presencia divina); b) la información de que dispone Pirgo: la verdadera Béroe ha quedado reposando por estar enferma y no ha podido asistir al duelo por Anquises (ningún dios homérico se encuentra con que su añagaza quede tan rápidamente desmontada por el mortal); c) la retirada portentosa desplegada finalmente por la deidad 25 .

Cabe destacar lo poco homérica que resulta la Iris protagonista de este episodio. La osadía y el afán y habilidad maquinadores ("haud ignara nocendi"; no se nos dice que la estratagema y la línea de actuación le hayan sido sugeridas por Juno) son bastante sorprendentes, sobre todo si se confrontan con la prudencia de la misma diosa en Homero. La actuación más atrevida de cuantas éste le atribuye es la del episodio en que, transfigurada en Laódice, incita a Hélena a ir al muro (Il. 3.122 ss.). Aquí Iris, empero, tiene movimientos y gestos serenos, y hace a Hélena una invitación que carece de las graves implicaciones conferidas por Virgilio a las exhortaciones de su personaje.

La misma mensajera es nuevamente puesta en marcha por Juno en 9.2 s.: "Irim de caelo misit Saturnia Iuno / audacem ad Turnum". El verso que expresa el encargo de la misión (9.2), por ser el ya utilizado en 5.606, adquiere carácter formular. El caudillo buscado, Turno, se encuentra retirado en el bosque de un valle sagrado ("luco tum forte parentis / Pilumni Turnus sacrata ualle sedebat", 3 s.). Iris lo interpela ("roseo Thaumantias ore locuta est", 5) y lo anima a aprovechar la momentánea ausencia de Eneas para efectuar un ataque contra los troyanos. Lą diosa emprende la marcha en seguida: "dixit, et in caelum paribus se sustulit alis / ingentemque fuga secuit sub nubibus arcum" (14 s.). Los términos son exactamente los mismos que han sido empleados para la retirada que ha dejado atónitas a las mujeres troyanas $(5.657 \mathrm{~s}$.), generándose la fórmula de verso entero $9.15=5.658$. También aquí, como cabe esperar, la deidad es reconocida ("agnouit", 16). El cielo que la acoge en su retirada ofrece al mortal un aspecto sorprendente ("medium uideo discedere caelum / palantisque polo stellas", 20 s.). El escenario es especial ("luco", "sacrata ualle"), la diosa ha desplegado desde el principio una actuación más franca y solemne que en el caso anterior y Turno, en consecuencia, vive la experiencia como algo prodigioso y positivamente numinoso. Todo se presta a que el caudillo rútulo exhiba una actitud piadosa: tomando en sus manos agua pura de un río eleva preces a los dioses (22 ss.).

De las alturas desciende el dios Apolo en busca de Ascanio en 9.644 s.: "ab alto aethere se mittit, spirantis dimouet auras / Ascaniumque petit". Apolo adopta la imagen de Butes ("forma tum uertitur oris / antiquum in Buten", 646 s.), un antiguo servidor de la casa de Anquises ("hic Dardanio Anchisae / armiger ante fuit fidusque ad limina custos", 647 s.) que Eneas más tarde ha puesto al servicio de su hijo ("tum comitem Ascanio pater addidit", $649)^{26}$. Del disfraz Virgilio se detiene con un interés especial en la voz, los cabellos y los

24 Afrodita es desenmascarada, entre otras cosas, por sus ǒ $\mu \mu \alpha \tau \alpha \mu \alpha \rho \mu \alpha i \rho o v \tau \alpha$ (Il. 3.397). Iris-Polites es descubierta por Héctor gracias a la voz (2.807). Cf. también $h$. Ven. 181.

25 Cf. Atena-Méntor en Od. $3.371 \mathrm{~s}$.

26 En Il. 17.323 ss. Apolo se transfigura en Perifante, servidor envejecido en la casa de Anquises, para instigar a Eneas a perseverar en la lucha (lo contrario de lo que el mismo dios quiere inspirar ahora a Ascanio). Virgilio, para 
accesorios: "omnia longaeuo similis uocemque coloremque / et crinis albos et saeua sonoribus arma" (650 s.). A diferencia de Iris-Béroe (5.649), y siguiendo la pauta homérica, Apolo cuida de simular también la voz del anciano ${ }^{27}$. Para marcharse, el dios, como Mercurio en 4.277 s., se disipa en el aire: "mortalis medio aspectus sermone reliquit / et procul in tenuem ex oculis euanuit auram" $(657 \mathrm{~s} \text {. })^{28}$. Los próceres troyanos reconocen a la divinidad ("agnouere deum", 659), presumiblemente, porque pueden contemplar su imagen genuina en el rápido instante que media entre el abandono del aspecto mortal y el desvanecimiento en el aire. Cabe pensar, en efecto, en una fugaz exhibición de la figura verdadera en el brevísimo intervalo que hay que suponer entre "reliquit" y "euanuit" 29 . En el aire queda suspendido un rastro del dios: el ruido causado por los pertrechos con los que acostumbra a moverse ("diuina tela / Dardanidae pharetramque fuga sensere sonantem", 659 s.). No las armas, sino el sonido generado por éstas, es lo que ayuda a confirmar la presencia divina (las huellas de Posidón en $\mathrm{Il}$. 13.71 realizan una función relativamente paralela).

Cuando Eneas está realizando una inspección por los parajes libios en compañía de Acates, la diosa Venus les sale al encuentro singularmente travestida: "mater media sese tulit obuia silua / uirginis os habitumque gerens et uirginis arma / Spartanae" (1.314 ss.). La deidad lleva rostro, traje y armas de muchacha desconocida. La relativa precisión ("uirginis... Spartanae") es del tipo de la que se aplica a Hermes-príncipe mirmidón en $I l$. 24.347 ss. El interés por los accesorios y por los detalles que ornan la figura supera al manifestado por Homero en su más larga descripción de un disfraz (Od. 13.222 ss.). De su hombro pende el arco de cazadora, lleva la cabellera suelta (319), la rodilla desnuda y los pliegues del vestido prendidos y sujetos de algún modo $(320)^{30}$. La estrategia de la diosa es singular: aborda a los personajes fingiendo una situación, la de que está interesada en saber de una hermana suya que hace un momento ha podido pasar por allí cazando (321 ss.). Eneas adopta una actitud muy semejante a la de Odiseo ante Nausícaa en Od. 6.149 ss. Ni el rostro ni la voz de la muchacha parecen, según el troyano, poseer naturaleza humana: "haud tibi uultus / mortalis, nec uox hominem sonat; o, dea certe / (an Phoebi soror? an Nympharum sanguinis una?)" (327 ss.). Venus entonces, sin querer todavía reconocer su verdadera identidad, pone a Eneas en conocimiento de la historia de Dido, la soberana de

hacer ver que el dios no ha hecho una elección absurda en lo tocante al disfraz, tiene que especificar que el personaje simulado no se ha quedado en Troya (649). De la cardadora lacedemonia en que Afrodita se transforma en Il. 3.385 ss. para ir a llamar a Hélena, no nos explica Homero si, ya que era sirvienta de la joven en Esparta, también ha venido siguiéndola hasta Troya.

27 Cf. J. Clay, "Demas and Aude: the Nature of Divine Transformation in Homer", Hermes 102 (1974), pp. 129-136.

$28 \mathrm{El}$ verso 658 es formular $(=4.278)$.

29 Nótese bien el interés del poeta, por lo demás manifiesto también en otras escenas, por dejar claro que el personaje realmente ve ante sí al dios ("ex oculis euanuit"). Los personajes virgilianos favorecidos por los dioses con estas experiencias, visualizan realmente la figura que se les presenta. No compartimos, pues, la opinión de G. Williams (Technique and Ideas in the Aeneid [Yale 1983], pp. 22 ss.) de que los mortales, en lo que a la exhibición del dios se refiere, sólo estarían asistiendo a una porción muy limitada de cuanto el poeta omnisciente cuenta a los lectoresoyentes.

30 Los cabellos que ondean y los ropajes son los detalles de la imagen de joven adoptada por Dioniso en el correspondiente himno homérico (4 ss.). 
aquella tierra (335 ss.). La diosa, además de desempeñar una tarea de orientación que recuerda la de Atena disfrazada de lugareña a las puertas de la ciudad feacia (Od. 7.19 ss. $)^{31}$, da al lector una información preciosa sobre el pasado de la reina cartaginesa. A la explicación que Eneas por su parte da de las calamidades que hasta el momento ha sufrido (372 ss.), sigue el discurso de invitación de la diosa a ir a presentarse en el dintel de Dido (387 ss.). La visita a esta reina, según la deidad, podría resultar extremamente provechosa. $\mathrm{Al}$ concluir su discurso e iniciar la retirada, parece que no le queda ya ningún inconveniente en descubrir a Eneas su verdadera naturaleza. Éste y su camarada comienzan a recibir indicios reveladores: "auertens rosea ceruice refulsit, / ambrosiaeque comae diuinum uertice odorem / spirauere; pedes uestis defluxit ad imos, / et uera incessu patuit dea", 402 ss.). Se trata de elementos convencionales: el cuello ( $c f . I l .3 .396, h$. Ven. 181), el cabello (cf. h. Cer. 279, A. R. 2.676 s.), la amplia vestimenta estatuaria ${ }^{32}$, el modo de caminar (Il. $13.71 \mathrm{~s}$.); se suma un elemento relativamente novedoso: el "diuinus odor" (presente ya en $h$. Cer. 277 s., donde es emanado por los ropajes de Deméter). El reconocimiento, como no podía ser menos, es inmediato: "matrem / agnouit (fugientem)" (405 s.). Con familiaridad, Eneas la interpela para reprocharle que haga uso de falaces apariencias cuando tiene que contactar con él (407 ss.). Venus emprende su retirada por los aires: no va al Olimpo, sino a uno de los lugares en donde se la venera y se le rinde culto ("ipsa Paphum sublimis abit sedesque reuisit / laeta suas", 415 s. $)^{33}$. Pero antes de esta retirada Virgilio introduce un elemento netamente homérico: la diosa, en su afán de que su intervención resulte en verdad operante y eficaz, rodea a los jóvenes con una densa niebla que los proteja de la posible curiosidad e indiscreción de los nativos (412 ss.) $)^{34}$.

Algo más tarde el héroe mismo cuenta la visita que nuevamente su madre, en este caso sin enmascarar la propia imagen, viene a hacerle durante el saqueo de Troya. Precisamente en el instante en que, en medio de la confusión, Eneas está por arremeter contra Hélena, la diosa se le aparece dispuesta a evitar el desastre que amenaza a su protegida: "talia iactabam et furiata mente ferebar, / cum mihi se, non ante oculis tam clara, uidendam / obtulit et pura per noctem in luce refulsit / alma parens, confessa deam qualisque uideri / caelicolis et quanta solet" (2.588 ss.). Venus busca el contacto físico con su hijo. Un gesto que en Homero es convencional, tocar la mano del mortal ${ }^{35}$, se convierte en esta escena en algo funcional: a la diosa le urge detener la agresiva iniciativa de Eneas ("dextraque prehensum / continuit", 592 s.). La intromisión de Venus tiene aquí la misma misión que el gesto de Atena en Il. 1.194 ss.: contener al protegido en el momento en que está a punto de matar a alguien también querido por la deidad. Impulsando al héroe a continuación a

\footnotetext{
31 Cf. el estudio comparativo de G. N. Knauer (Die Aeneis und Homer [Göttingen 1964], pp. 158 ss.).

32 El atuendo de Afrodita es operante cuando Anquises la ve por vez primera ( $h$. Ven. 86 ss.).

33 Los versos son un eco de la retirada a Pafos de Afrodita en el episodio cantado por Demódoco (Od. 8.362 ss.).

34 En Feacia la niebla figura desde el inicio (Od. 7.14 ss.) y, entre otras cosas, cobija la intervención de Atena (19 ss.).

35 Es elemento recurrente en las apariciones de la Nereida Tetis. Ésta acaricia a su hijo en Il. 1.361 y 24.127, y le toma la mano en 19.7. La misma diosa agarra la mano de Peleo al presentársele en A. R. 4.852. Sobre las connotaciones del contacto físico entre la deidad y el visitado, $c f$. G. Aquaro, "Alle soglie dell'Tliade: quel fascino accecante", SIFC 77 (1984), p. 147.
} 
abandonar Troya, Venus contribuye, como Atena en dicho episodio homérico, a la fluidez y continuidad del desarrollo narrativo ${ }^{36}$. La diosa hace a su hijo la proposición de disiparle de los ojos la densa y sombría nube que le impide, en su calidad de mortal, advertir la presencia de los dioses olímpicos en medio de toda la devastación ("omnem, quae nunc obducta tuenti / mortalis hebetat uisus tibi et umida circum / caligat, nubem eripiam", 604 ss.). Eneas tiene así la posibilidad de descubrir, inmiscuidos en la terrible refriega y en la destrucción de la ciudad, a los dioses más importantes (610 ss.) ${ }^{37}$. Tan excepcional contemplación es determinante. Tras admitir que los olímpicos están irremisiblemente contra Troya ("apparent dirae facies inimicaque Troiae / numina magna deum", 622 s.), Eneas entiende que lo más sensato y prudente es emprender sin dilación la marcha. Venus efectúa su retirada ocultándose entre las sombras ("spissis noctis se condidit umbris", 621), modo de desaparecer que se adecúa a la circunstancia cronológica y a las dramáticas condiciones de deterioro y destrucción del escenario.

La diosa Venus reitera el contacto físico instantes antes de emprender la retirada en su aparición de 8.608 ss. Tras desplazarse entre las nubes portando las armas que ha fabricado Vulcano, encuentra a su hijo separado de los otros en un valle apartado: "natumque in ualle reducta / ut procul egelido secretum flumine uidit, / talibus adfata est dictis seque obtulit ultro" (609 ss.). La soledad de Eneas y el carácter del escenario, un valle retirado con una corriente, recuerdan la situación de Turno en 9.3 ss. Tras hablar, y antes de colocar las resplandecientes armas bajo una encina, Venus busca el abrazo de su hijo: "amplexus nati Cytherea petiuit" (615). Su injerencia se concluye automáticamente. Su desaparición del escenario no es ni siquiera referida. El idílico escenario virgiliano se aparta de la costa poblada en la que Tetis se encuentra con su hijo para entregarle las armas en Il. $19.3 \mathrm{ss.} \mathrm{El}$ contacto físico figura aquí al principio: nada más llegar y antes de hablar, Tetis, como es típico, toma la mano de Aquiles (7). Después de colocarle las armas ante los pies (12 s.), la Nereida tiene aún tiempo para intercambiar con él algunas palabras (se trata de aprovechar que en ese momento justamente el escenario se ha quedado despoblado: la vista de las temibles armas ha hecho que los mirmídones huyan espantados, $14 \mathrm{~s}$.).

Cuando ya todo está preparado para la partida de tierra cartaginesa y Eneas duerme en su nave, le hace Mercurio su segunda visita. Virgilio apunta que el instante es justamente el del descanso nocturno ("Aeneas celsa in puppi iam certus eundi i carpebat somnos", 4.554 s.). La deidad, que tiene la habilidad de introducirse en las representaciones oníricas del mortal, se aparece sin máscara ni disfraz ("huic se forma dei uultu redeuntis eodem / obtulit in somnis rursusque ita uisa monere est, / omnia Mercurio similis, uocemque coloremque / et crinis flauos et membra decora iuuenta", 556 ss.). El dios pretende truncar el reposo ("potes hoc sub casu ducere somnos?", 560) e instigar a Eneas a hacerse de inmediato al mar. La retirada tiene el aspecto de un deshacerse de la imagen del dios en la tiniebla nocturna ("sic fatus nocti se immiscuit atrae", 570). Eneas, aterrado, se sacude el sueño

36 Cf. P. Pucci, op. cit. 1985, p. 180.

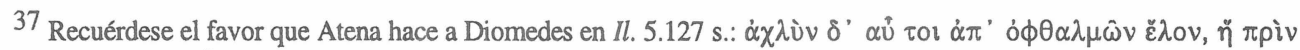

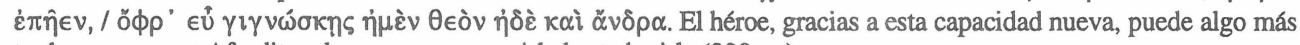
tarde reconocer a Afrodita y lanzarse a perseguirla hasta herirla (330 ss.). 
("subitis exterritus umbris / corripit e somno corpus", 571 s.) y, sin demorarse, empuja a los hombres a efectuar por fin la partida (572 ss.).

En Creta, en el contexto de la peste que arrasa la ciudad recientemente fundada, recibe Eneas la visita nocturna de los Penates. A la aparición precede la notación temporal: "nox erat et terris animalia somnus habebat" $(3.147)^{38}$. El personaje reconoce que las deidades se le muestran en el interior de su sueño ("in somnis"), pero, paradójicamente, el resplandor que las ilumina y les da nitidez no es otro que el que la luna filtra por la ventana: "uisi ante oculos astare iacentis / in somnis multo manifesti lumine, qua se / plena per insertas fundebat luna fenestras" (150 ss.). Los Penates tienen, lógicamente, un mensaje que transmitirle ("tum sic adfari et curas his demere dictis", 153); Eneas justifica su estupor ante lo visto y oído ("talibus attonitus uisis et uoce deorum", 172) por la autenticidad que la viveza y diafanidad de las imágenes logran imprimir a la experiencia: "nec sopor illud erat, sed coram agnoscere uultus / uelatasque comas praesentiaque ora uidebar" (173 s.). Ver a los dioses en el contexto de los propios sueños no priva, pues, de veracidad a la aparición. Es significativa en este sentido la insistencia de Eneas en la claridad con que ha podido ver a los Penates ("multo manifesti lumine") ${ }^{39}$. El héroe presenta un síntoma físico de miedo: "gelidus toto manabat corpore sudor" (175). Abandona precipitadamente el reposo: "corripio e stratis corpus" (176), alza las manos al cielo y realiza súplicas y libaciones (176 ss.).

La notación temporal que introduce la epifanía de Tiberino está algo más elaborada: "nox erat et terras animalia fessa per omnis / alituum pecudumque genus sopor altus habebat" (8.26 s.). Eneas ha tenido la ocurrencia, en su gran aflicción ("tristi turbatus pectora bello", 29), de acomodarse sobre la ribera del río ("procubuit seramque dedit per membra quietem", 30). Tiberino se hace ver surgiendo de entre la vegetación ("huic deus ipse loci fluuio Tiberinus amoeno / populeas inter senior se attollere frondes / uisus [eum tenuis glauco uelabat amictu / carbasus, et crinis umbrosa tegebat harundo]", 31 ss.) para dirigir a Eneas un discurso tranquilizador ("tum sic adfari et curas his demere dictis", 35). El aspecto de la deidad es el genuino; está sin duda más elaborado y adaptado que la simple imagen de hombre exhibida por el Escamandro en Il. 21.213. En medio de las instrucciones, el dios estimula al héroe a tener por real cuanto está viendo ("ne uana putes haec fingere somnum", 42). Tiberino advierte que su imagen y su discurso no forman parte de las inconsistentes representaciones oníricas en las que tan hábilmente ha sabido introducirse. Acto seguido efectúa su retirada sumergiéndose en las aguas ("dixit, deinde lacu fluuius se condidit alto / ima petens", 66 s.) 40 . Concluye la noche y el reposo ("nox

38 Advierte S. M. Nicoll ("Ovid, Amores 1.5", Mnemosyne 30 [1977], p. 43, n. 11) que las fórmulas de apertura "nox erat" y "tempus erat" son empleadas por Virgilio sólo en el contexto de las apariciones.

39 Cf. 2.589 s.: "non ante oculis tam clara, uidendam / obtulit et pura per noctem in luce refulsit". La claridad y distinción con que son contemplados los objetos en una aparición ayudan a diferenciar una visión auténtica de un sueño ordinario ( $c f$. W. S. Nicoll, op. cit., p. 45, n. 13).

40 Tiberino no se desvanece. Simplemente regresa a su medio. Realiza la escapada que es típica entre deidades acuáticas, sobre todo entre aquellos dioses marinos y fluviales que acaban de hacer de la propia realidad física una exposición real y franca. Al abismo oceánico retornan Idotea (Od. 4.425), Proteo (570), Leucotea (5.352); PosidónEnipeo se sumerge en el río (11.253). Cf. también Glauco en A. R. 1.1326 ss., Tetis en 4.865, Tritón en 4.1618 ( $\delta \hat{u}^{\delta}{ }^{\prime}$ 
Aenean somnusque reliquit", 67); el héroe se levanta y eleva sus preces a las deidades del lugar tras tomar en sus manos aguas del río ("rite cauis undam de flumine palmis / sustinet ac talis effundit ad aethera uoces", 69 s.).

Las Ninfas en que en su momento quedaron convertidas las naves hacen su visita a Eneas durante la noche: "dies caelo concesserat almaque curru / noctiuago Phoebe medium pulsabat Olympum" (10.215 s.). El héroe, insomne y atribulado ("neque enim membris dat cura quietem", 217), controla el rumbo de la nave. En este caso las deidades no tienen que hacer el esfuerzo de introducirse en el sueño del personaje. Es Cimodoce, la más docta en el discurso, la que se ocupa de interpelar al héroe. El contacto físico es de inspiración apoloniana: "pone sequens dextra puppim tenet ipsaque dorso / eminet ac laeua tacitis subremigat undis" (226 s.) ${ }^{41}$. El discurso se inicia con una variación y adaptación de un interrogante típico: "uigilasne, deum gens, / Aenea?" (228 s. $)^{42}$. Cuando la deidad ha terminado de hablar, impulsa la nave antes de soltarla y emprende veloz la retirada por las aguas ("fugit illa per undas / ocior et iaculo et uentos aequante sagitta", 247 s.). Eneas se siente atónito ("stupet inscius", 249) y de inmediato eleva una plegaria ("supera aspectans conuexa precatur", 251).

La visita de Somnus a Palinuro es realizada, merced a los turbios objetivos, con procedimientos engañosos. Es la media noche ("iamque fere mediam caeli Nox umida metam / contigerat, placida laxabant membra quiete / sub remis fusi per dura sedilia nautae", 5.835 ss.) y Palinuro, sin probar el sueño, está dirigiendo la armada. Somnus desciende abriéndose paso entre las tinieblas para traer al piloto un triste destino: "leuis aetheriis delapsus Somnus ab astris / aëra dimouit tenebrosum et dispulit umbras, / te, Palinure, petens, tibi somnia tristia portans / insonti" (838 ss.). Tomando el aspecto de Forbas ("Phorbanti similis", 842), se sienta en la popa y hace al piloto un discurso falaz y astuto con la intención de hacerle descuidar su tarea. Palinuro se muestra como el timonel perito y prudente que es. No se fía de la bonanza del mar y redobla el celo con que hasta el momento se ha empeñado en su trabajo. Somnus entonces le agita sobre las sienes una rama empapada en las aguas del Leteo (854 ss.). Tras inclinarse sobre él para hacerlo precipitarse al mar, se retira en dirección opuesta: "uolans tenuis se sustulit ales ad auras" (861).

También Alecto elige la noche para entrar en acción. Quien la pone en marcha es Juno, que desciende a la tierra (7.323) para evocarla y hacerla salir de las tinieblas infernales. El encargo que le hace es el de instigar enfrentamientos entre Eneas y Latino. Juno reconoce a la otra su capacidad como maquinadora y su riqueza en artificios (335 s.) y deja en sus manos la búsqueda y elección de un plan concreto (338 s.). Alecto actúa en primer lugar sobre la reina Amata (343 ss.), por supuesto sin que ésta advierta el manejo siniestro de que es objeto. Acto seguido se encamina a la ciudad de Turno (408). Éste es hallado sumido en

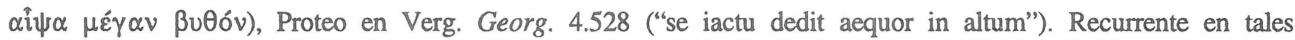
indicaciones es la noción de que el dios entra en el agua buscando las profundidades ("lacu ... alto / ima petens", Aen. $8.66 \mathrm{~s}$.).

41 Glauco emerge del mar sólo parcialmente (A. R. 1.1312 s.). Asoma su cabeza y su pecho y ase con su mano el codaste de la nave Argo (1313).

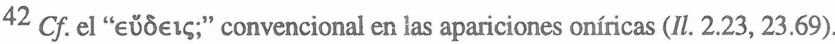


profundo sueño ("mediam nigra carpebat nocte quietem", 414). Alecto entonces se transfigura: se deshace de su imagen terrorífica ("toruam faciem et furialia membra / exuit", 415 s.) y se transforma en Cálibe, una sacerdotisa de Juno. Contra la pauta típicamente homérica en el tratamiento de los disfraces no anónimos, hay singulares detalles descriptivos de la imagen de anciana adoptada: "in uultus sese transformat anilis / et frontem obscenam rugis arat, induit albos / cum uitta crinis, tum ramum innectit oliuae; / fit Calybe Iunonis anus templique sacerdos, / et iuueni ante oculos his se cum uocibus offert" (416 ss.). Turno no toma en serio el mensaje de la sacerdotisa y se burla de ella (435), lo que provoca la ira de Alecto. Es un hecho insólito que el durmiente visitado aventure palabras de respuesta. El temblor se apodera de él ("subitus tremor occupat artus, I deriguere oculi", $446 \mathrm{~s}$.) ante la horrorosa imagen que repentinamente se despliega ante sus ojos: un monstruo de ojos inquietos ("flammea torquens / lumina", 448 s.) lleno de

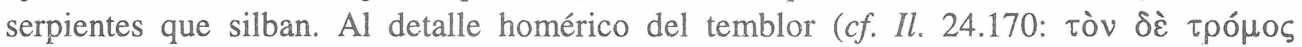

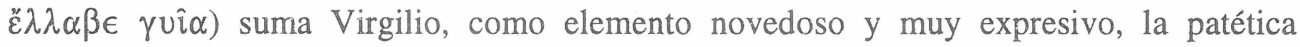
rigidez de los ojos, el helarse de la mirada. La terrible imagen despierta a Turno ("somnum ingens rumpit pauor", 458), quien se ve cubierto de sudor ("ossaque et artus / perfundit toto proruptus corpore sudor", $458 \mathrm{~s}$. $)^{43}$ y no duda en pasar de inmediato a la acción violenta sugerida por la Furia (460 ss.). El terrorífico desenmascaramiento trunca el sueño de Turno, y al mismo tiempo le despierta la conciencia del riesgo que lo amenaza.

De las seis apariciones nocturnas, cuatro discurren durante el sueño (Mercurio, Penates, Tiberino, Alecto) y dos se desarrollan ante un personaje que está en vela (Eneas, 10.217; Palinuro, 5.841). Ambas pautas cuentan con precedentes homéricos. En estado de vigilia, y mientras todos los demás duermen, recibe Telémaco la visita de una Atena no disfrazada en

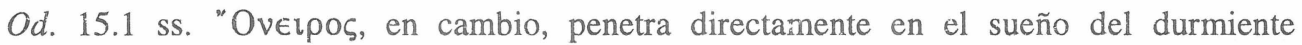
Agamenón (Il. 2.20 ss.) e inicia su discurso con un reproche semejante al hecho por

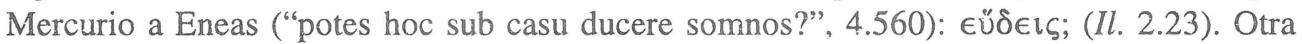
deidad homérica que realiza su visita introduciéndose en el sueño es Atena en Od. 6.15 ss.

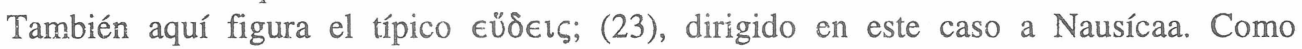
"Oveıpos, y comı Somnus y Alecto, también Atena se dirige a la princesa feacia tras disfrazarse de personaje conocido (22 ss.).

Una vez revisadas todas las escenas aportadas por Virgilio, hemos de llamar la atención sobre una serie de detalles y de características generales. Júpiter y Juno, como Zeus en Homero, evitan contactar directamente con los hombres. Así, son justamente ellos quienes promueven las intervenciones de Mercurio y de Iris (sólo la segunda injerencia del primero, la nocturna de 4.554 ss., parece tener una relativa autonomía). En el manejo de los roles asignados a Mercurio y a Iris tal vez es Virgilio más riguroso que Homero, quien por su parte no tiene ningún reparo en presentar como embajadores y mensajeros de Zeus y Hera a otros dioses: Atena en $I l .1 .195$ ss., 2.166 ss., 4.68 ss., Apolo en 15.221 ss. ${ }^{44}$. Por otra parte,

43 En Homero es típico que las deidades menores no necesiten disfraz. Su exposición no suele representar un peligro para el mortal ( $c f$. H. J. Rose, "Divine Disguisings", HTR 49 [1956], pp. 65 s.). Aquí, en cambio, el desenmascaramiento resulta brutal. Turno vive la visión de la auténtica Alecto como una experiencia, no devastadora, pero sí cruelmente aterradora y agresiva.

44 Nos parece una llamativa singularidad virgiliana que Juno envíe en 4.693 ss. a Iris a realizar una misión que 
con sus escenas de epifanía, Virgilio también da relieve a deidades que no son precisamente las más preponderantes en el mundo heroico de Homero. Aunque ya en la Odisea, como luego también en Apolonio de Rodas, divinidades menores acuáticas aparecen en alguna ocasión realizando injerencias importantes, en la acción épica homérica son casi siempre los olímpicos los más decididos a inmiscuirse y a intervenir activamente en las actuaciones de los hombres. El papel y la momentánea relevancia que Virgilio da a Tiberino, los Penates, Iuturna y las Ninfas, además de recordar la afición apoloniana por la epifanía de grupos de dioses y de deidades menores, pueden explicarse por el interés en dar participación a deidades autóctonas y por el deseo de realzar en general el ámbito itálico en el que la acción tiene su desenvolvimiento.

El mortal más visitado es, como cabía esperar, el propio Eneas: un total de ocho ocasiones. Sigue Turno con tres visitas: la escena protagonizada por Iris, la aparición nocturna de Alecto y el encuentro con Iuturna sobre el campo de batalla. El único caso de epifanía experimentada por la colectividad es el de 5.606 ss. (Iris-Béroe y las troyanas). En los parajes libios (1.314 ss.) Eneas vive el encuentro con Venus-cazadora acompañado por Acates, pero nada hace pensar que este personaje, a quien Virgilio convierte en una presencia muda, haya podido experimentar la epifanía con la misma intensidad que el héroe protagonista. Homero, por su parte, presenta varios casos de actuación de la deidad ante la multitud: Atena-heraldo ( $I l .2 .280$ ss.), Ares-Acamante (5.461 ss.), Hera-Esténtor (5.780 ss.); y un caso de epifanía ante una pareja de mortales: Posidón y los dos Ayaces (Il. 13.45 ss.).

En dos ocasiones, 5.619 s. y 7.415 ss., Virgilio expresa la adquisición de una nueva apariencia sumando los siguientes instantes: a) anulación de la imagen genuina; b) "fit" seguido de un nombre propio. En el resto de los casos en que hay que indicar la adopción

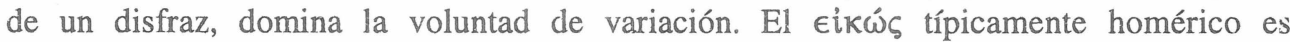
recordado en 5.842 ("Phorbanti similis") y, lo que es bien llamativo, en un caso en el que verdaderamente no hay máscara: "omnia Mercurio similis, uocemque coloremque" (4.558), verso forjado sobre $I l$. 21.600b 'A үৃฑ์

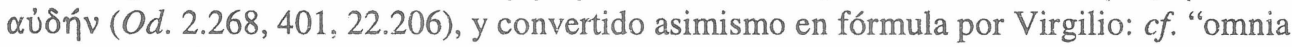
longaeuo similis uocemque coloremque" (9.650).

Hay un solo caso de disfraz anónimo: Venus transfigurada en cazadora espartana. "Virginis Spartanae" va referido al aspecto de la joven (ropaje corto, dinamismo propio de una atleta o cazadora) y no tanto a su verdadero origen. Hay que pensar, más bien, que se trata, en la intención de Virgilio, de una nativa. Es como la lugareña anónima en que se transforma Atena en las afueras de la ciudad feacia ( $O d .7 .20$ ss.). El único propósito, en uno y otro caso, es el de que el personaje, sin alentar los comentarios y las suspicacias de la población, pueda recibir información y orientación.

Normalmente el disfraz no evita que el mortal llegue a percibir que tiene delante a una deidad. A este grado de entendimiento puede llegar el personaje de dos maneras: a) gracias a los indicios que el dios le permite atrapar (Iris-Béroe y Venus-cazadora los dan durante su actuación y también en el momento de la retirada; Apolo-Butes en el instante de marcharse; 
el caso de Alecto-Cálibe es especial: antes de irse se muestra con su imagen genuina, gesto con el que trata de dar fuerza de persuasión a su mensaje); b) por una habilidad o una capacidad de penetración que no nos son explicadas: Iuturna aparece junto a Turno bajo el aspecto del auriga Metisco (12.623 s.) y dirigiendo el carro del caudillo rútulo. Éste reconoce a su hermana instantáneamente (632 ss.). En este caso el factor determinante es, sin duda, el estrecho vínculo de parentesco ${ }^{45}$. Ambas vías de reconocimiento del dios cuentan con antecedentes en Homero: a) el dios disfrazado revela su identidad al final de su intervención en $I l .21 .600$ ss. (Apolo-Agénor), 24.347 ss. (Hermes-joven mirmidón), Od. 11.235 ss. (Posidón-Enipeo). En los tres casos el autodesenmascaramiento es sólo verbal: el dios descubre su añagaza pero, a lo que parece, no se muestra tal cual es. Es también importante recordar que a menudo los dioses de Homero, como la Venus-cazadora virgiliana o Iris-Béroe antes de delatarse con la espectacular escapada, consienten complacidos que el héroe por sí solo vaya adivinando o sospechando su naturaleza divina por un porte especial y un físico no vulgar; b) el disfraz del dios es penetrado por el mortal instantáneamente, sin que se nos explique muy bien cómo, en $\mathrm{Il} .17 .323$ ss. (ApoloPerifante). No es del gusto virgiliano el tipo homérico de epifanía en que sólo el poeta y el lector saben que ante el personaje se encuentra una deidad enmascarada (Il. 2.280 ss., 3.122 ss., 4.68 ss., 17.555 ss., 582 ss.).

Virgilio trata la epifanía como un acontecimiento mucho más extraordinario de cuanto parece serlo para Homero. Como fenómeno, es bastante más esporádico; figura allí donde el propósito u objetivo que ha de alcanzarse, difícilmente podría ser logrado por otros medios: sólo Venus, como la Tetis homérica, puede entregar a su hijo las armas fabricadas por Vulcano. A Turno las instrucciones de Juno no pueden serle transmitidas sino a través de Iris. La aparición de los Penates está tomada de la tradición según la cual estas deidades habrían manifestado repetidamente su voluntad a lo largo de la expedición ${ }^{46}$. Por lo demás, los dioses carecen en la Eneida de la gran afición a descender y a moverse por la esfera humana que exhiben en los poemas homéricos. No recorren los dominios humanos con la facilidad con que en la Ilíada atraviesan el campo de batalla, huyen en general de diálogos prolijos con los mortales (del tipo de $O d .13 .226$ ss.) y, por supuesto, no acompañarían a los personajes con la continuidad y tenacidad con que Atena-Méntor lo hace en la Telamaquia. Sólo el caso de Iuturna-Metisco se sale relativamente de la tónica que Virgilio pretende hacer prevalecer. Hermana de Turno, y elevada incidentalmente por Zeus al rango divino, la Ninfa asiste por breve tiempo al caudillo rútulo sobre el campo de batalla. Su retirada, efectuada en el dramático momento en que se advierte impotente para salvar al hermano, marca en el poema el inicio de la cuenta atrás en la vida de éste.

Que la epifanía es un acontecimiento trascendental lo revela también la reacción misma del mortal. A esta reacción otorga Virgilio una atención para la que hallamos escasas referencias o correspondencias en Homero. En los casos más solemnes el personaje adopta una actitud piadosa: Turno (9.22 ss.) y Eneas (3.176 ss., 8.69 s., 10.251) elevan preces y

\footnotetext{
45 Tampoco esta presencia sobrenatural, como la siniestra visita de Alecto, permite al personaje pensar que cuenta con el apoyo divino; es más, él mismo manifiesta a Iuturna que es consciente de que el favor de los dioses ya no está de su parte ("superis auersa uoluntas", 647).
}

46 Cf. R. Heinze, Virgil's epische Technik (Stuttgart 1965), p. 313. 
votos. La eventual presencia de un río permite además, como se ha visto, un ritual especial. Con estas escenas ofrece una ligera semejanza Od. 13.354 ss.: tras el diálogo con Atena, y tras reconocer por fin, despejada ya la niebla por obra de la diosa, que la que lo rodea es verdaderamente la deseada tierra de Ítaca, Odiseo besa el suelo y con las manos alzadas ora a las Ninfas del lugar. El enmudecimiento y el erizarse de los cabellos son en 4.279 s. los síntomas del miedo de Eneas. En 571 se siente "exterritus". Ante los Penates, el cuerpo se le cubre de un sudor frío (3.175). Atónito queda en 10.249 al ver a las Ninfas. Iris-Béroe deja a las troyanas estupefactas y, al mismo tiempo, peligrosamente enardecidas y llenas de arrojo (5.659). Turno por su parte se aterra cuando ve a Alecto: tiembla, abre y fija los ojos de un modo doloroso (7.446 s.) y se despierta finalmente cubierto de sudor (458 s.). Los dos únicos lugares en que Homero introduce detalles de este tipo pertenecen al último canto de la Ilíada (versos 170 y 358 ss.) y están ambos protagonizados por Príamo. En 24.170 se recoge el temblor de los miembros. En 358 ss. son mencionados el aturdimiento y el

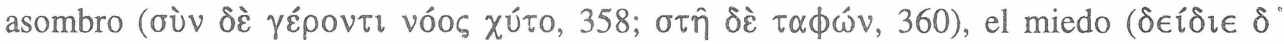

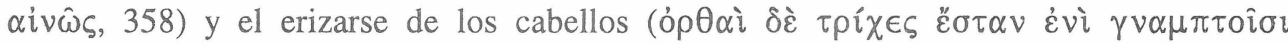
$\mu \varepsilon ́ \lambda \in \sigma \sigma 1,359)$. El enmudecimiento es, como ya se ha dicho, ingrediente presente en $h$. Cer. $282^{47}$. La mirada se convierte en un detalle operante en algunas epifanías apolonianas (A. R. 2.681 s., 4.1316), donde, empero, no adquiere el significado y el dramatismo aportados por el "deriguere oculi" aplicado a Turno (7.447). El detalle recurrente del sudor constituye, por su parte, una aportación particular de Virgilio. Indudablemente, la imagen del personaje que el miedo consigue trastornar, queda normalmente descrita por nuestro poeta con una viveza y una plasticidad para las que es difícil hallar alguna justa correspondencia en Homero o en Apolonio. Por último, la actitud de Turno vuelve a ser patética en un caso que no hemos citado: al ver que la Furia, transfigurada en el ave nocturna de los cementerios, vuela en torno a él golpeándole el escudo con las alas, experimenta un enervamiento

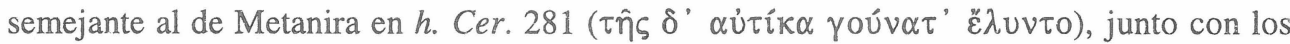
síntomas padecidos por Eneas en 4.280: "membra nouus soluit formidine torpor, I arrectaeque horrore comae et uox faucibus haesit" (12.867 s.). La Furia es sólo reconocida desde lejos por Iuturna (869), quien, comprendiendo con amargura el funesto agüero, renuncia finalmente a seguir asistiendo al hermano $y$, en lo que sin duda constituye un acto convencional ( $c f . n .40$ ), bien que algo inesperado por tratarse de una divinidad no acuática, se retira de la escena adentrándose en el río: "caput glauco contexit amictu / multa gemens et se fluuio dea condidit alto" ( $885 \mathrm{~s}$.).

\footnotetext{
47

7 En la Ilíada y la Odisea se suele relegar el desvanecimiento de la voz a situaciones que pueden también a veces ser de asombro y perplejidad, pero que nada tienen que ver con las apariciones de los dioses (Il. 8.28 ss., 9.430 ss., 693 ss.).
} 